\title{
Comment on "Radiative forcings for 28 potential Archean greenhouse gases" by Byrne and Goldblatt (2014)
}

\author{
R. V. Kochanov ${ }^{1,2}$, I. E. Gordon ${ }^{1}$, L. S. Rothman ${ }^{1}$, S. W. Sharpe ${ }^{3}$, T. J. Johnson ${ }^{3}$, and R. L. Sams ${ }^{3}$ \\ ${ }^{1}$ Harvard-Smithsonian Center for Astrophysics, Atomic and Molecular Physics Division, Cambridge MA, USA \\ ${ }^{2}$ Laboratory of Quantum Mechanics of Molecules and Radiative Processes, Tomsk State University, Tomsk, Russia \\ ${ }^{3}$ Pacific Northwest National Laboratory, Richland WA, USA
}

Correspondence to: I. E. Gordon (igordon@cfa.harvard.edu)

Received: 21 April 2015 - Published in Clim. Past Discuss.: 22 May 2015

Accepted: 10 August 2015 - Published: 25 August 2015

\begin{abstract}
In the recent article by Byrne and Goldblatt, "Radiative forcing for 28 potential Archean greenhouse gases," Clim. Past. 10, 1779-1801 (2014), the authors employ the HITRAN2012 spectroscopic database to evaluate the radiative forcing of 28 Archean gases. As part of the evaluation of the status of the spectroscopy of these gases in the selected spectral region $\left(50-1800 \mathrm{~cm}^{-1}\right)$, the cross sections generated from the HITRAN line-by-line parameters were compared with those of the PNNL database of experimental cross sections recorded at moderate resolution. The authors claimed that for $\mathrm{NO}_{2}, \mathrm{HNO}_{3}, \mathrm{H}_{2} \mathrm{CO}, \mathrm{H}_{2} \mathrm{O}_{2}, \mathrm{HCOOH}, \mathrm{C}_{2} \mathrm{H}_{4}, \mathrm{CH}_{3} \mathrm{OH}$ and $\mathrm{CH}_{3} \mathrm{Br}$ there exist large or sometimes severe disagreements between the databases. In this work we show that for only three of these eight gases a modest discrepancy does exist between the two databases and we explain the origin of the differences. For the other five gases, the disagreements are not nearly at the scale suggested by the authors, while we explain some of the differences that do exist. In summary, the agreement between the HITRAN and PNNL databases is very good, although not perfect. Typically differences do not exceed $10 \%$, provided that HITRAN data exist for the bands/wavelengths of interest. It appears that a moleculedependent combination of errors has affected the conclusions of the authors. In at least one case it appears that they did not take the correct file from PNNL $\left(\mathrm{N}_{2} \mathrm{O}_{4}\right.$ (dimer) $+\mathrm{NO}_{2}$ was used in place of the monomer). Finally, cross sections of $\mathrm{HO}_{2}$ from HITRAN (which do not have a PNNL counterpart) were not calculated correctly in BG, while in the case of HF misleading discussion was presented there based on the confusion by foreign or noise features in the experimental PNNL spectra.
\end{abstract}

\section{Introduction}

In their recent article, Byrne and Goldblatt (Byrne and Goldblatt, 2014a) (hereafter denoted as BG) studied the radiative forcings for 28 Archean gases. To calculate these forcings, they used the line-by-line section of the HITRAN2012 spectroscopic database (Rothman et al., 2013).

The HITRAN database is considered the international standard for the spectroscopic parameters of the gases that are major terrestrial atmospheric absorbers of light at different wavelengths. The database consists of experimental, theoretical, and semi-empirical parameters from laboratories all over the globe. Before the data appear in HITRAN they undergo a validation process (e.g., see Fig. 1 of the HITRAN2012 paper) including comparisons with independent lab spectra. The database is used by tens of thousands of researchers and industrial engineers for a great variety of applications. The database is being constantly updated by improving the accuracy of the existing line parameters as well as by adding new bands, new molecules, and new isotopologues.

The PNNL set is a strictly experimental database recorded at moderate resolution $\left(0.1 \mathrm{~cm}^{-1}\right)$ with all species pressurebroadened to 760 Torr during measurement using pure $\mathrm{N}_{2}$ gas. By definition, it includes all experimental effects in its results such as hot bands, combination bands, pressure broadening, and the effects of (potential) trace contaminants (Sharpe et al., 2004; Johnson et al., 2010). Great care is taken to identify these experimental effects by analyzing multiple aliquots $(\sim 10)$ of samples at various partial pressures. For example, a composite spectrum might be derived from aliquots containing $0.1,0.25,0.5,5,10,50$, etc. Torr of sam- 


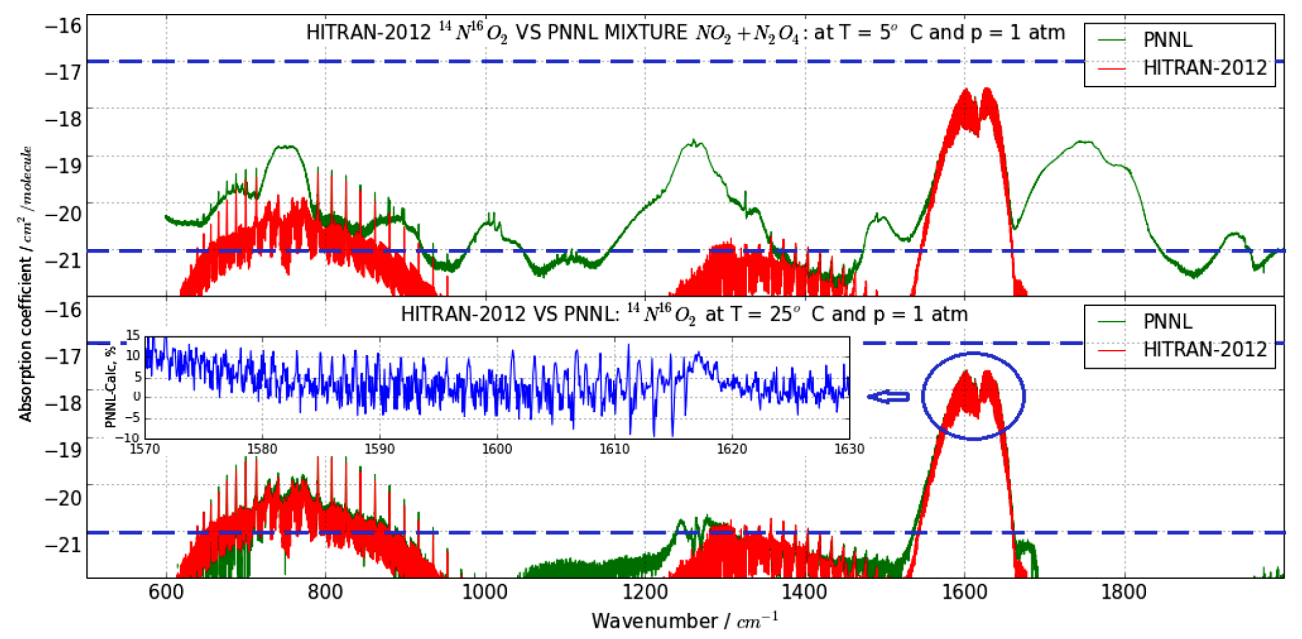

Figure 1. Comparison of HITRAN with PNNL: case of $\mathrm{NO}_{2}$. The top panel shows cross sections from $\mathrm{PNNL}_{\text {for }}$ the mixture of $\mathrm{N}_{2} \mathrm{O}_{4}$ and $\mathrm{NO}_{2}$ (green trace) compared to HITRAN NO 2 data as was done in the $\mathrm{BG}$ article. The bottom panel compares $\mathrm{NO}_{2}$ from $\mathrm{PNNL}_{\mathrm{N}}$ to $\mathrm{NO}_{2}$ in HITRAN showing very good agreement. The area inside the thick dashed horizontal grid lines corresponds to the area shown in the panels of Fig. 1 in the BG article.

ple, which are then pressure-broadened to 760 Torr using UHP nitrogen. Any discrepancies introduced by contaminants, partial pressure errors, baseline drift, etc. will manifest in the residuals of the composite or fitted spectrum.

In BG, as part of the evaluation of the spectroscopy of the selected 28 Archean gases in the spectral region of interest, the cross sections generated from the HITRAN lineby-line parameters were compared with the ones provided in the PNNL database of experimental cross sections (Sharpe et al., 2004). The LBLABC code (Meadows and Crisp, 1996) was used by BG for generating cross sections from HITRAN data. The comparison is visualized in Fig. 1 of the BG paper and includes a corresponding discussion. The authors claimed that for eight out of the 28 gases there are large or sometimes extreme disagreements between the two databases. These gases are nitrogen dioxide $\left(\mathrm{NO}_{2}\right)$, nitric acid $\left(\mathrm{HNO}_{3}\right)$, formaldehyde $\left(\mathrm{H}_{2} \mathrm{CO}\right)$, hydrogen peroxide $\left(\mathrm{H}_{2} \mathrm{O}_{2}\right)$, formic acid $(\mathrm{HCOOH})$, ethylene $\left(\mathrm{C}_{2} \mathrm{H}_{4}\right)$, methanol $\left(\mathrm{CH}_{3} \mathrm{OH}\right)$, and methyl bromide $\left(\mathrm{CH}_{3} \mathrm{Br}\right)$. For instance, for the latter gas the authors claim that HITRAN overestimates absorption coefficients by 2 orders of magnitude. The authors take into account these discrepancies when evaluating possible errors in their calculation of the radiative forcings when using HITRAN (see their Fig. 11 and discussion around it).

These conclusions have a serious impact on the trust of potential users of both the HITRAN and PNNL databases. For instance, $\mathrm{NO}_{2}$ is a very important atmospheric gas and it is imperative that the HITRAN database contains a reliable line list for this gas. In this work we have repeated the authors' calculations using the HITRAN Application Programming Interface (HAPI) (Kochanov, 2015). HAPI is a tool that we are developing and that will be distributed with the HITRAN editions in the future. It allows downloading, filtering, and sophisticated absorption calculations using the HITRAN data. Our calculations show that for only three of these gases $\left(\mathrm{HNO}_{3}, \mathrm{H}_{2} \mathrm{CO}\right.$ and $\left.\mathrm{HCOOH}\right)$ do disagreements observed by the authors exist, and we explain their origin. For the other five gases, the disagreements are not nearly at the scale suggested by the authors, while we explain some of the subtler differences that do exist. It appears that a combination of errors might have affected the authors' conclusions. With certainty we can tell that at least in one case $\mathrm{BG}$ did not take the correct file from the PNNL database. $\left(\mathrm{N}_{2} \mathrm{O}_{4}+\mathrm{NO}_{2}\right.$ was used in place of $\mathrm{NO}_{2}$ ).

In this article, the details of the calculations using HAPI are briefly described at the beginning. We then show the results that unambiguously demonstrate that the disagreements between HITRAN and PNNL, although they do exist, are not at the disastrous scale suggested by BG. The differences that are observed are then discussed and we conclude that they are mostly associated with either a few missing bands in HITRAN or with impurities in the PNNL spectra. We separate the findings into five categories: (1) when BG compare incorrect entities, i.e., when they compare $\mathrm{N}_{2} \mathrm{O}_{4}$ from PNNL with $\mathrm{NO}_{2}$ from HITRAN, (2) when our comparison plots (for $\mathrm{H}_{2} \mathrm{O}_{2}, \mathrm{C}_{2} \mathrm{H}_{4}, \mathrm{CH}_{3} \mathrm{OH}$ and $\mathrm{CH}_{3} \mathrm{Br}$ ) look nothing like the ones shown in Fig. 1 of the BG paper, with the agreement of HITRAN and PNNL being substantially better than in BG plots, (3) when our plots (for $\mathrm{HNO}_{3}, \mathrm{H}_{2} \mathrm{CO}$ and $\mathrm{HCOOH}$ ) look basically the same as those from the BG paper, (4) when there was no PNNL measurement available but the calculations carried out by BG using HITRAN data are incorrect (case of $\mathrm{HO}_{2}$ ), (5) the case of $\mathrm{HF}$ where some noise or an impurity in the PNNL spectrum in the $800-2000 \mathrm{~cm}^{-1}$ region was assumed as a real HF absorption by BG. 


\section{Computational method}

Absorption coefficients were calculated using line-by-line data from the HITRAN2012 database. For the calculation of absorption coefficients, we have used the new software HAPI (HITRAN Application Programming Interface), which was recently created at the Harvard-Smithsonian Center for Astrophysics. For the basic algorithm of cross-section calculation, one can follow the appendix of the HITRAN1996 paper (Rothman et al., 1998). The capabilities of HAPI are briefly outlined later in this section.

Cross sections were calculated for thermodynamic conditions that were used when obtaining experimental data available in the PNNL database (Sharpe et al., 2004; Johnson et al., 2010). For constructing cross sections for each molecule, we have used isotopologues available in HITRAN2012 in proportion to their abundance in the terrestrial atmosphere (as defined in HITRAN and also available in HAPI).

There are two important issues that one has to remember when comparing PNNL cross sections with those generated from the HITRAN database, although none of these issues are important when plotting the cross-section on the logarithmic scale as was done in the BG paper: (1) in the experiments that produced PNNL database files that are considered here, nitrogen was used as a buffer gas whereas the HITRAN database provides broadening and shifting parameters for air, i.e. a mixture of nitrogen and oxygen. In general the broadening parameters for air and $\mathrm{N}_{2}$ are different by factors that depend on the molecular species and even rovibrational transitions within these species. Nevertheless, for the purpose of this work it is quite sufficient to just use air-broadened values and that is what was used here. (2) At this time most of the HITRAN files do not include line-mixing which may account for some few percent differences in the cross sections, especially around the band heads.

Since we compare our calculations with the PNNL measurements at 5 and $25^{\circ} \mathrm{C}$ and a pressure of $1 \mathrm{~atm}$, we consider the Doppler broadening to be small compared to collisional broadening. For that reason, we applied a simple Lorentzian profile for all molecules. To properly simulate the experiment, we apply the instrumental function as suggested in the description by PNNL: boxcar apodization with $0.112 \mathrm{~cm}^{-1}$ spectral resolution. An interesting point to be made is that the $\mathrm{BG}$ paper claims that all the comparisons are done at $5{ }^{\circ} \mathrm{C}$, but the PNNL database does not even contain data at this temperature for $\mathrm{NO}_{2}, \mathrm{H}_{2} \mathrm{O}_{2}$ and $\mathrm{HCOOH}$. For these molecules, we made a comparison at $25^{\circ} \mathrm{C}$ only. Also, because partial pressures of all considered gases were small compared to the buffer gas $\left(\mathrm{N}_{2}\right)$, we consider the selfbroadening as a negligible effect compared to the broadening by $\mathrm{N}_{2}$. All absorption cross sections were calculated using a step of $0.01 \mathrm{~cm}^{-1}$, and each line wing was considered to be 50 HWHMs (half width at half maximum) from the center of the line.
A few details about HAPI should be given. Currently it is written in Python and gives the ability to filter, analyze, and transform line-by-line spectral data and calculate cross sections from it. The current version of HAPI provides several basic spectral functions (absorption, transmittance, and radiance) at arbitrary values of pressure, temperature, and optical path length. The user can obtain the most recent version of HAPI and its manual from the HITRANonline site (www.hitran.org). Apart from the conventional line profiles Doppler, Lorentz, and Voigt, HAPI also introduces a Python implementation of the Hartmann-Tran (HT) isolated hard collision line profile (Ngo et al., 2013; Tennyson et al., 2014).

For temperature-dependence of the absorption coefficients, HAPI contains partition sums for isotopologues which are most abundant in the terrestrial atmosphere. All these partition sums were taken from TIPS-2011 (Laraia et al., 2011). It is worth noting that partition sums for the $\mathrm{CH}_{3} \mathrm{OH}$ molecule are not provided in TIPS-2011 and in this work were taken from the parsum.dat file that was distributed with the HITRAN2004 database (Rothman et al., 2005) which in turn were provided by authors of Xu et al. (2004).

For absorption coefficient, HAPI uses a flexible functional approach, in which the user can control a great part of the aspects of calculation via function parameters. For instance, controllable are thermodynamic parameters $(p, T)$, wavenumber grid parameters (step, range), intensity cutoff, line-wing sizes, etc.

To better simulate gas mixtures, the user can apply custom broadening mechanisms considering the self-broadening, airbroadening (standard HITRAN-supported) and more complex foreign broadening schemes (applicability of such schemes depend on the presence of non-standard broadening parameters for a particular spectral line).

Apart from that, custom line profiles, partition sums, and instrumental functions can be used without a need to rewrite the HAPI code itself. This makes HAPI a powerful tool to calculate cross sections from the line-by-line data, provided by the HITRAN database (or potentially any similar line list of spectroscopic parameters). A Python program that interacts with HAPI in order to calculate cross sections generated here is provided in the supplementary material.

\section{PNNL observations vs. calculations based on the HITRAN database}

In this section we give the cross sections calculated here using HITRAN2012 line-by-line data compared with the experimental cross sections of PNNL. We made comparisons at the temperature of $5^{\circ} \mathrm{C}$ whenever it was possible. For the cases in which the data of PNNL do not include $5^{\circ} \mathrm{C}$, we used the $25^{\circ} \mathrm{C}$ data sets and compared them to our calculations at $25^{\circ} \mathrm{C}$. All experimental spectra considered here were measured at $760 \pm 5$ Torr pressure. In our calculations, the pressure was set to 760 Torr (i.e., $1 \mathrm{~atm}$ ). Table 1 gives a sum- 
Table 1. Characteristics of PNNL data on considered molecules.

\begin{tabular}{|c|c|c|}
\hline Molecule & $\begin{array}{l}\text { Temperature, } \\
{ }^{\circ} \mathrm{C}\end{array}$ & $\begin{array}{l}\text { PNNL comments on possible impurities } \\
\text { including those subtracted) }\end{array}$ \\
\hline $\mathrm{NO}_{2}$ & $25 \pm 2$ & $\mathrm{~N}_{2} \mathrm{O}_{4}, \mathrm{NOCl}[0.48 \%], \mathrm{NO}[0.33 \%], \mathrm{HNO}_{3}[0.15 \%]$ and $\mathrm{H}_{2} \mathrm{O}[0.13 \%]$ \\
\hline $\mathrm{CH}_{3} \mathrm{Br}$ & $5.03 \pm 0.02$ & Dimethyl Ether $\left(\mathrm{CH}_{3} \mathrm{OCH}_{3}\right)[0.10 \%]$ \\
\hline $\mathrm{C}_{2} \mathrm{H}_{4}$ & $5.03 \pm 0.02$ & - \\
\hline $\mathrm{H}_{2} \mathrm{CO}^{1}$ & $5.00 \pm 0.02$ & Air, $\mathrm{CO}_{2}$, polymers, water vapor \\
\hline $\mathrm{HCOOH}$ & $25 \pm 2$ & $\begin{array}{l}\text { Water contamination }[4.70 \%] \text { (corrected by rescaling and } \\
\text { spectral subtraction). Dimer features present at } 3400-2500,1736 \text {, } \\
1365,1221 \text { and } 926 \mathrm{~cm}^{-1} \text {. }\end{array}$ \\
\hline $\mathrm{H}_{2} \mathrm{O}_{2}$ & $25 \pm 2$ & $\begin{array}{l}50 \% \text { hydrogen peroxide was distilled in house to } 82.78 \% \text { by weight } \\
\text { which is } 70.698 \% \text { by volume. } \mathrm{H}_{2} \mathrm{O} \text { was subtracted. }\end{array}$ \\
\hline $\mathrm{CH}_{3} \mathrm{OH}$ & $4.98 \pm 0.02$ & $\begin{array}{l}\text { Air, Water. Multiple freeze-thaw cycles at }-60^{\circ} \mathrm{C} \text { to remove air. } \\
\text { Sample placed over } \mathrm{CaSO}_{4} \text { for removal of water. }\end{array}$ \\
\hline $\mathrm{HNO}_{3}{ }^{2}$ & $5.05 \pm 0.02$ & $\begin{array}{l}\text { Individual absorbance spectra corrected and accounted for } \mathrm{H}_{2} \mathrm{O} \text {, } \\
\mathrm{CO}_{2}, \mathrm{NO}, \mathrm{NO}_{2}, \mathrm{~N}_{2} \mathrm{O} \text { and } \mathrm{HCl} \text { contamination. }\end{array}$ \\
\hline
\end{tabular}

${ }^{1}$ Extremely unstable due to rapid polymerization. ${ }^{2}$ Extremely reactive. Undergoes rapid decomposition when exposed to heat and reducing agents (e.g., metals, organics...).

mary of the experimental conditions that were employed by PNNL for the individual molecules which are in the focus of our comment paper. This table contains information on thermodynamic conditions, stability of samples, and both the potential and observed (subtracted) impurities. Indeed, some experiments are really non-trivial when it comes to stability of the samples, for instance the $\mathrm{H}_{2} \mathrm{O}_{2}$ experiment was especially challenging and it is described in Johnson et al. (2009).

One should also keep in mind that the PNNL data do not exist below $600 \mathrm{~cm}^{-1}$ as this is out of the region of the detectors employed in these experiments.

The calculated difference between the PNNL and HITRAN databases based on our present calculations (for the specified molecules, described in Sects. 3.1 and 3.2, over the specified wavenumber ranges) are summarized in Table 2, along with the observations/comments of the BG paper for the same molecules. The values in the third column show differences between integrated areas $(\Delta=$ (HITRANPNNL)/HITRAN $\times 100 \%$ ) in the spectral intervals specified in the second column. In most cases the agreement is very good, except for certain molecules which are chemically very challenging.

\section{$3.1 \quad \mathrm{NO}_{2}$}

Figure 1 shows the $\mathrm{NO}_{2}$ cross sections calculated from the HITRAN data and their comparison with PNNL experimental cross sections for both the $\mathrm{N}_{2} \mathrm{O}_{4}+\mathrm{NO}_{2}$ mixture (top panel) and the pure $\mathrm{NO}_{2}$ (bottom panel). When compared to the BG plot in their Fig. 1b, 9th panel, it unambiguously shows that $\mathrm{BG}$ were actually comparing $\left(\mathrm{N}_{2} \mathrm{O}_{4}+\mathrm{NO}_{2}\right)$ PNNL spectra with HITRAN $\mathrm{NO}_{2}$ spectra. At the same time we show that the agreement between the PNNL and HITRAN databases is very good. The zoomed spectral region inset shows that differences do exist, nevertheless, and they are attributed largely to experimental impurities described in Table 1, lack of line-mixing parametrization and hot bands in HITRAN, as well as aforementioned differences between broadening by pure nitrogen vs. that by air.

\section{2 $\mathrm{H}_{2} \mathrm{O}_{2}, \mathrm{C}_{2} \mathrm{H}_{4}, \mathrm{CH}_{3} \mathrm{OH}$, and $\mathrm{CH}_{3} \mathrm{Br}$}

Figure 2 shows the $\mathrm{H}_{2} \mathrm{O}_{2}, \mathrm{C}_{2} \mathrm{H}_{4}, \mathrm{CH}_{3} \mathrm{OH}$, and $\mathrm{CH}_{3} \mathrm{Br}$ cross sections calculated from the HITRAN2012 line-by-line data and their comparison with corresponding experimental cross sections from the PNNL database. One can clearly see that the agreement between the PNNL and HITRAN line-byline data, although not perfect, is substantially better than the way it appears in the BG paper which claims that the PNNL/HITRAN disparity is factors of two or more in some cases, and more than an order of magnitude in others. We also note that for the cases of $\mathrm{H}_{2} \mathrm{O}_{2}$ and $\mathrm{CH}_{3} \mathrm{OH}$, the $\mathrm{BG}$ calculation of cross-section is overestimated in comparison with our calculation, which agrees well with PNNL. In the region of interest the data for $\mathrm{H}_{2} \mathrm{O}_{2}$ in HITRAN is derived based on Devi et al. (1986), Klee et al. (1999), and Perrin et al. $(1995,1996)$. The data for $\mathrm{CH}_{3} \mathrm{OH}$ originates from $\mathrm{Xu}$ et al. (2004). As seen in Table 2, for $\mathrm{C}_{2} \mathrm{H}_{4}$, on the contrary, BG underestimates the absorption when it employs HITRAN data. Our calculation shows that the agreement between PNNL and HITRAN is quite good. The differences between the data underneath strong peaks largely reflect uncertainties given for the corresponding intensity data in HITRAN, keeping in mind all other effects that were described earlier for the case of $\mathrm{NO}_{2}$. The blow up of the differences around $1440 \mathrm{~cm}^{-1}$ shows large residuals which we attribute to possibly missing hot bands in HITRAN and lack of line-mixing parameterization. In the selected spectral re- 
Table 2. Differences between HITRAN and PNNL for molecules for which conclusions were erroneous in BG.

\begin{tabular}{llll}
\hline Molecule & $\begin{array}{l}\text { Integration limits } \\
\mathrm{cm}^{-1}\end{array}$ & $\Delta^{\mathrm{a}}$ & Erroneous conclusion in $\mathrm{BG}^{\mathrm{b}}$ \\
\hline $\mathrm{CH}_{3} \mathrm{OH}$ & $947.7-1090.9$ & $0.7 \%$ & Over an order of magnitude larger \\
$\mathrm{H}_{2} \mathrm{O}_{2}$ & $1175.7-1369.8$ & $+5 \%$ & More than twice larger \\
$\mathrm{CH}_{3} \mathrm{Br}$ & $547.8-1097.2$ & $-19 \%$ & About 13 times larger \\
& $1242.6-1335.1$ & $-14 \%$ & \\
& $1334.8-1625.5$ & $-16 \%$ & \\
$\mathrm{C}_{2} \mathrm{H}_{4}$ & $825.5-1160.0$ & $-16 \%$ & About an order of magnitude lower \\
& $1381.6-1515.6$ & $-10 \%$ & \\
$\mathrm{HF}^{\mathrm{c}}$ & $3581.9-4336.8$ & $+7 \%$ & HITRAN and PNNL do not overlap \\
$\mathrm{NO}_{2}$ & $635.5-923.5$ & $-13 \%$ & About an order of magnitude lower and missing multiple bands \\
& $1518.9-1728.6$ & $-0.6 \%$ & \\
\hline
\end{tabular}

${ }^{\mathrm{a}} \Delta=\left(\right.$ HITRAN - PNNL)/HITRAN $\times 100 \% .{ }^{\mathrm{b}}$ BG comments in terms of HITRAN data with respect to PNNL. ${ }^{\mathrm{c}}$ HITRAN and PNNL overlap perfectly; it is just that absorption is very weak in the region considered by BG.

gions the ethylene data in HITRAN is based on the works of Blass et al. (2001), Brannon and Varanasi (1992), Cauuet et al. (1990), Legrand et al. (1995), Rotger et al. (2008), and Rusinek et al. (1998). Finally, for $\mathrm{CH}_{3} \mathrm{Br}$, BG overestimates absorption calculated using HITRAN. This mistake is visually enhanced in their Fig. 1 due to the apparent fact that what they present as PNNL cross sections does not actually correspond to the PNNL values and are weaker. $\mathrm{CH}_{3} \mathrm{Br}$ data in HITRAN originate from Jacquemart et al. (2007) and Kwabia Tchana et al. (2004). It is worth mentioning that HITRAN indeed is missing a relatively strong $v_{3}$ band at $611 \mathrm{~cm}^{-1}$ as well as some hot bands in the region between the $v_{2}\left(1335 \mathrm{~cm}^{-1}\right)$ and $v_{5}\left(1445 \mathrm{~cm}^{-1}\right)$ bands as can be seen from the zoomed insert in the corresponding panel of Fig. 2.

\section{3 $\mathrm{HNO}_{3}, \mathrm{H}_{2} \mathrm{CO}$, and $\mathrm{HCOOH}$}

Figure 3 shows the $\mathrm{HNO}_{3}, \mathrm{H}_{2} \mathrm{CO}$, and $\mathrm{HCOOH}$ cross sections calculated from the HITRAN data and their comparison with corresponding experimental cross sections from the PNNL database. We find the same differences between the databases as did the BG paper. In fact, the lack of some of the important $\mathrm{HNO}_{3}$ bands is repeatedly noticed in the remotesensing community (see for instance discussion in the HITRAN2008 paper, Rothman et al., 2009). Unfortunately, although we introduce major improvements into every new edition of HITRAN (for instance in HITRAN2012 $\mathrm{H}^{15} \mathrm{NO}_{3}$ isotopologue data were added based on Perrin and Mbiaké, 2006 and validated in Brizzi et al., 2009) the lack of highresolution reliable data in many regions prevents the modeling of the missing bands. A similar situation, but slightly less dramatic for remote-sensing applications, exists for $\mathrm{H}_{2} \mathrm{CO}$. Most notably HITRAN is missing the $\nu_{3}$ band at $1500 \mathrm{~cm}^{-1}$. There is a plan to add this band based on the work of (Perrin et al., 2003) into the next edition of HITRAN. Finally, major differences between the PNNL and HITRAN databases for formic acid are attributed to the impurities (especially dimer) in the experimental spectrum (see Table 1). HITRAN is missing strong $\nu_{7}$ and $\nu_{9}$ bands located at $\sim 630 \mathrm{~cm}^{-1}$. There is a lack of intensity information to generate a comprehensive line list in this region although the information on the energy levels involved in the transitions is fairly complete for calculation of the line positions (Perrin et al., 2002; Baskakov et al., 2006). It is interesting that differences that do exist in the strong bands that are present in both databases seem to manifest themselves in between the strong lines (see Fig. 4). It could be that (1) there is a broad continuum-like feature due to an impurity that underlies the PNNL spectrum in that region, and/or (2) for experimental spectra it is sometimes very difficult to assign a zero baseline to subtract, especially in cases where it must be assigned under a broad, complex spectral band or bands.

\section{$3.4 \quad \mathrm{HO}_{2}$}

Figure 5 shows the cross sections for $\mathrm{HO}_{2}$ calculated based on the HITRAN data. Comparing Fig. 5 with Fig. 1 from the BG paper it is clear that the corresponding cross sections are not calculated correctly there (they are underestimated).

\section{$3.5 \mathrm{HF}$}

Finally, although the plot for HF in Fig. 1 of the BG paper correctly represents the data in the databases, the discussion around it is quite incorrect. They state: "the HITRAN and PNNL data do not overlap. The HITRAN data are available below $500 \mathrm{~cm}^{-1}$ and PNNL data are available above $\sim 900 \mathrm{~cm}^{-1}$ ". Their statement is very misleading. The HITRAN2012 database is very complete for the HF molecule. The HF line list is described in the HITRAN2012 paper and given in more detail in $\mathrm{Li}$ et al. (2013). One problem is that PNNL obviously had some noise issue or an impurity in the $800-2000 \mathrm{~cm}^{-1}$ region. That is why it may seem that there is an HF absorption in that region if looking at the PNNL spectra in Fig. 1 of the BG paper. For HF the PNNL fo- 


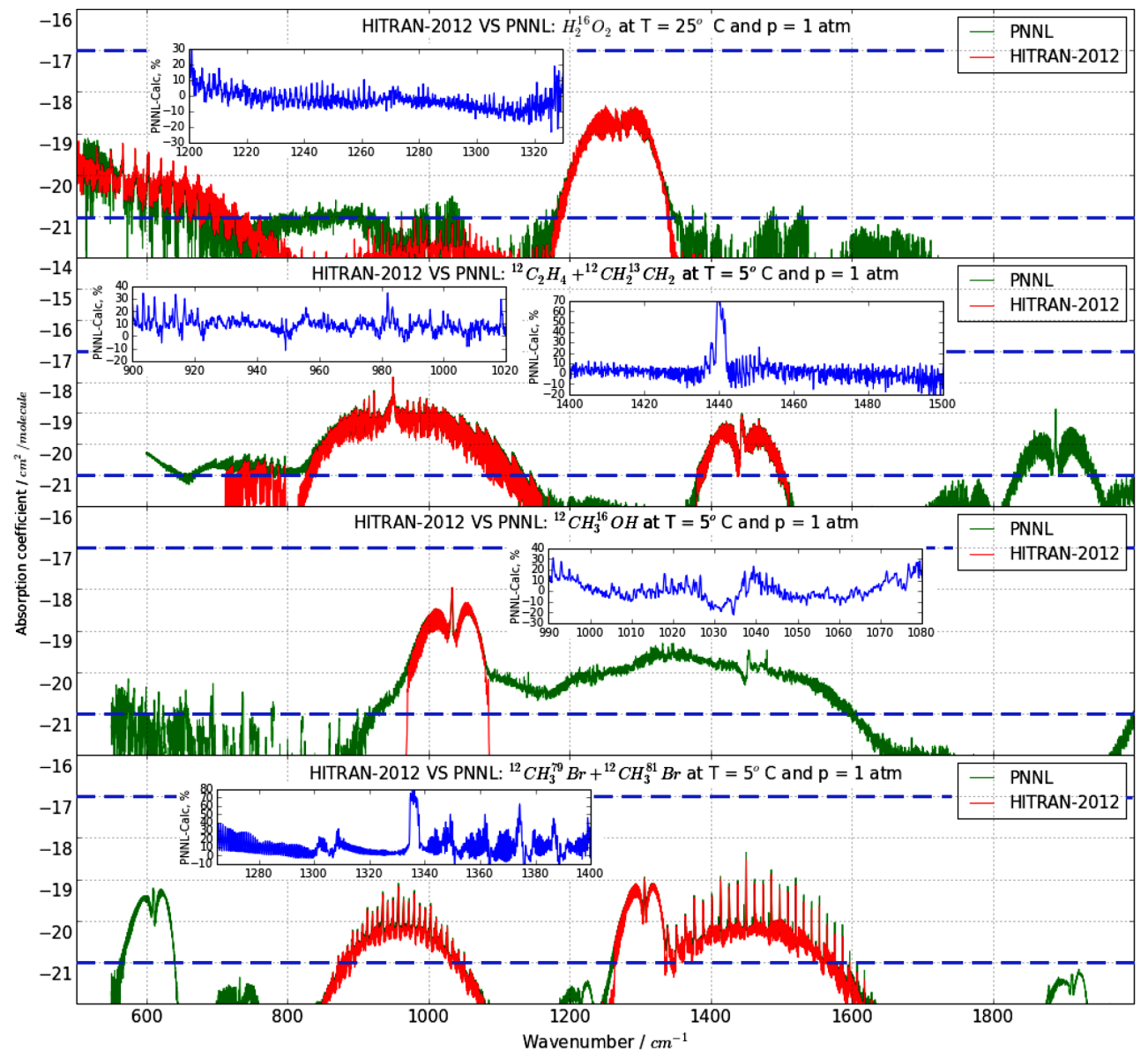

Figure 2. Comparison of HITRAN with PNNL: from top to bottom $\mathrm{H}_{2} \mathrm{O}_{2}, \mathrm{C}_{2} \mathrm{H}_{4}, \mathrm{CH}_{3} \mathrm{OH}, \mathrm{CH}_{3} \mathrm{Br}$. The area inside the thick dashed horizontal grid lines corresponds to the area shown in the panels of Fig. 1 in the BG article.

cus was only on the spectral region of the $v_{1}$ fundamental at wavenumbers $\geq 4000 \mathrm{~cm}^{-1}$.

In summary, our calculated absorption coefficients agree well with experimental data for the considered temperatures and pressure. Contrary to the conclusions of the BG paper, we find that the disagreements are mostly unnoticeable on the logarithmic scale in the places of strongest absorption. In the zoomed regions we show comparison on a linear scale with residuals. We considered mostly these regions, in which the HITRAN2012 database is known to have enough data to reproduce the real absorption correctly. Most of these residuals are less than 20 to $30 \%$. For some Q-branches, however, they can reach $70 \%$. This effect can be due to the strong line mixing that may occur in these branches. For most of the strongest absorption bands, the agreement corresponds well with the error codes supplied with the HITRAN database. Naturally the agreement is worse for the bands with weaker absorption due to the absence of lines in the database or to impurities in experimental data.

It is worth mentioning that the residuals between PNNL's data and our calculations are mostly above zero. For in- stance, for formaldehyde the agreement is fine for the line peaks (5-10\% for the error code 5 and $10-20 \%$ for the error code 4$)$, whereas the line wings give more systematic error (see Fig. 4).

\section{Conclusions}

In this comment we have shown that the differences between the PNNL and HITRAN databases are not nearly as severe as was purported in the BG paper, in most cases they differ by only $20 \%$ or much less, not by an order of magnitude or more as claimed. In particular, in the cases of $\mathrm{H}_{2} \mathrm{O}_{2}$, $\mathrm{HO}_{2}, \mathrm{C}_{2} \mathrm{H}_{4}, \mathrm{CH}_{3} \mathrm{OH}$, and $\mathrm{CH}_{3} \mathrm{Br}$ it is clear that $\mathrm{BG}$ did not calculate cross sections correctly from the HITRAN line-byline data. In the case of $\mathrm{CH}_{3} \mathrm{Br}$ it also seems that the PNNL cross sections shown by BG in their Fig. 1 are much weaker than those in the real PNNL database. We cannot tell on the logarithmic scale of that figure if that may be the case for other molecules. However, in the case of $\mathrm{NO}_{2}, \mathrm{BG}$ clearly appear to have used the $\mathrm{N}_{2} \mathrm{O}_{4}+\mathrm{NO}_{2}$ cross sections from PNNL when comparing to HITRAN $\mathrm{NO}_{2}$ data. 


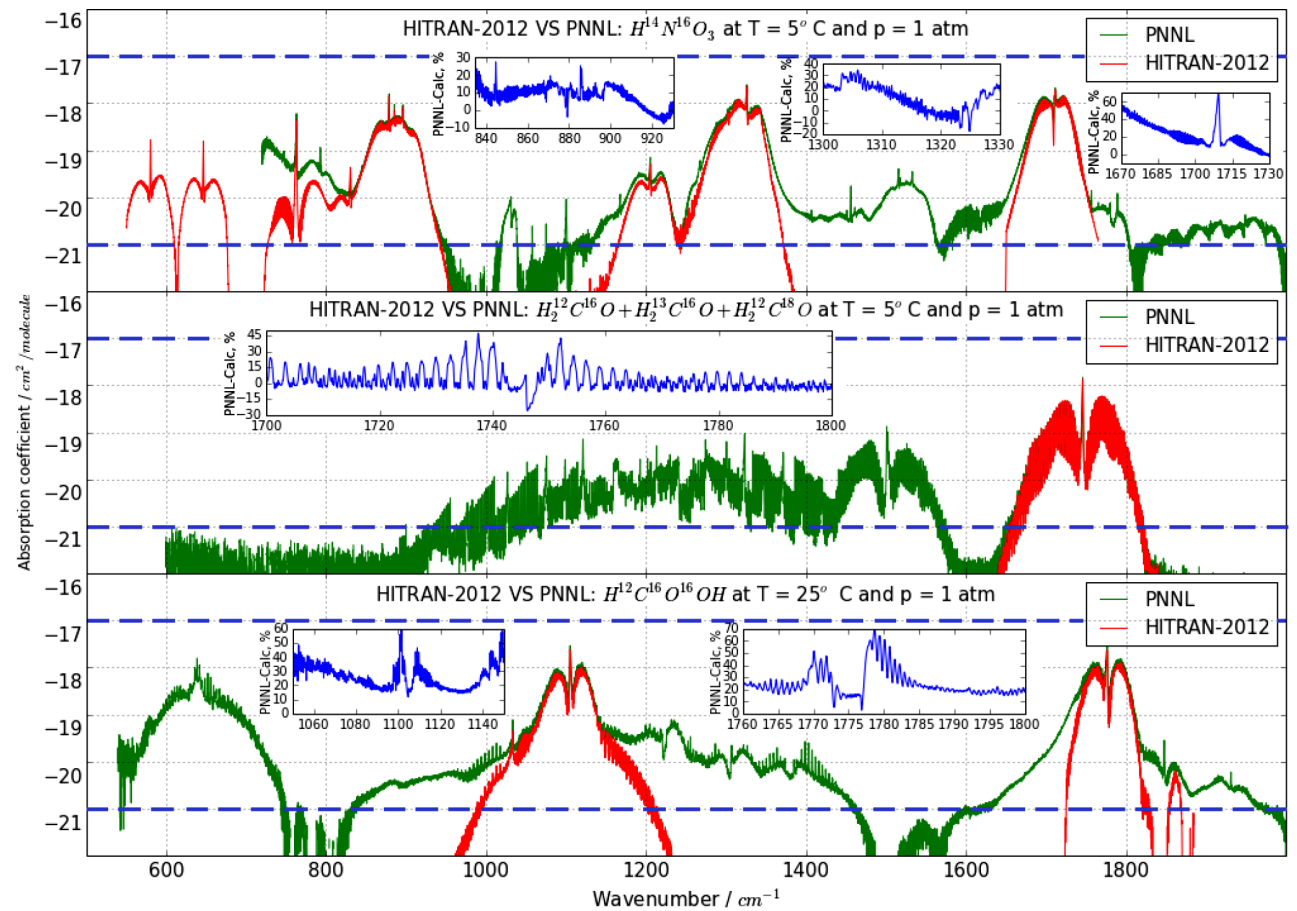

Figure 3. Comparison of HITRAN with PNNL: from top to bottom $\mathrm{HNO}_{3}, \mathrm{H}_{2} \mathrm{CO}, \mathrm{HCOOH}$. The area inside the thick dashed horizontal grid lines corresponds to the area shown in the panels of Fig. 1 in the BG article.

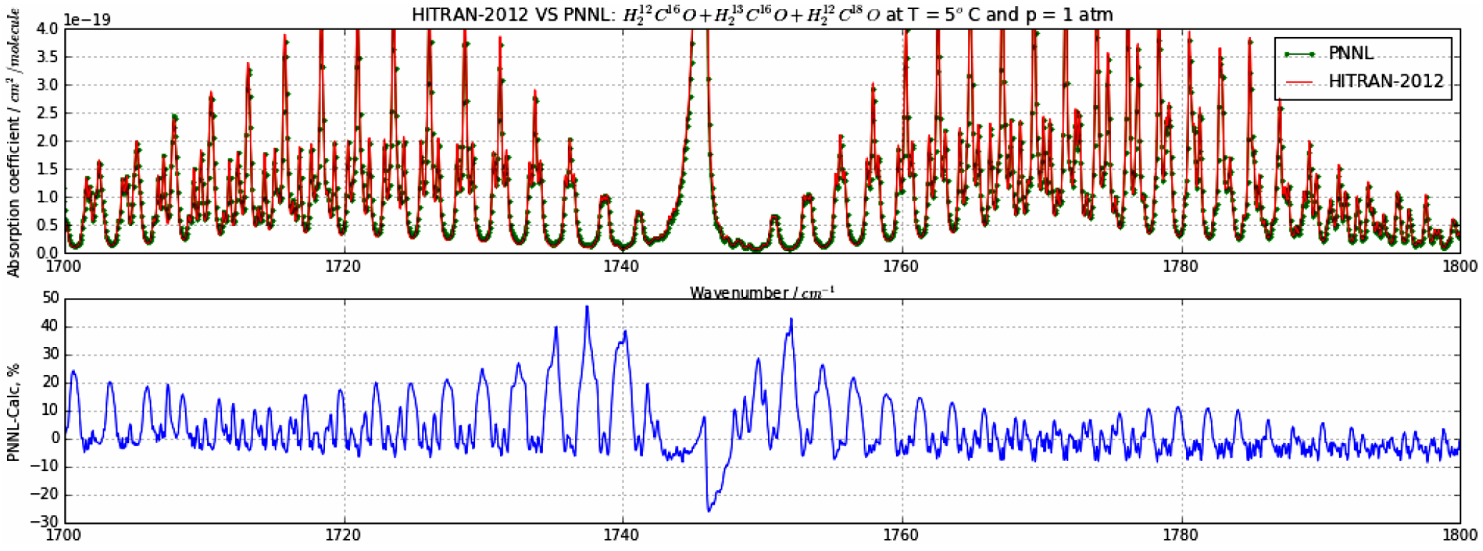

Figure 4. Residuals between calculated and experimental cross sections of $\mathrm{H}_{2} \mathrm{CO}$ in the $1700-1800 \mathrm{~cm}^{-1}$ spectral region.

In their other paper (Byrne and Goldblatt, 2014b) it is mentioned that they take cross sections from the Virtual Planetary Laboratory (VPL) and give the following link http://depts.washington.edu/naivpl/content/ molecular-database. We could not find any actual data at that address, only graphical overviews of the data from PNNL. With that we note that under the $\mathrm{NO}_{2}$ link at that site one can find the figure showing the $\mathrm{N}_{2} \mathrm{O}_{4}+\mathrm{NO}_{2}$ absorption. In fact, thanks to our interactions with thousands of researchers across the globe we can state that the most common error associated with using HITRAN or PNNL data is the use of data that were obtained not from the databases themselves, but from secondary sources and were very likely altered at some point. It is important to note there is no intention on our part to cast any doubt on (Byrne and Goldblatt, 2014b) and the topic of this comment is strictly the (Byrne and Goldblatt, 2014a) paper.

We believe that the endeavor of the BG authors to simulate the Archean atmosphere is a commendable one. We also think that their general approach to calculate radiative forcings is correct. Unfortunately, the conclusion of this comment is that for the gases discussed here, Figs. 1, 11 and discussions around them in the BG paper are incorrect. Consequently, the radiative forcings calculated there for the afore- 


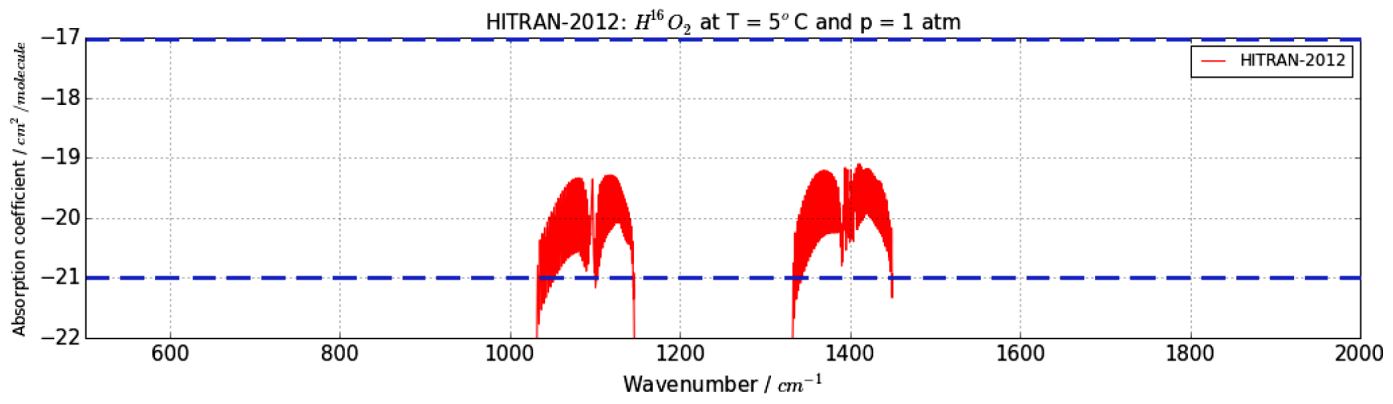

Figure 5. Cross sections generated from the HITRAN data for $\mathrm{HO}_{2}$. The area inside the thick dashed horizontal grid lines corresponds to the area shown in the panels of Fig. 1 in the BG article.

mentioned molecules are in error. At the same time, certain discrepancies do in fact exist for $\mathrm{HNO}_{3}, \mathrm{H}_{2} \mathrm{CO}$ and $\mathrm{HCOOH}$ and are mostly due to the missing bands in HITRAN and to a lesser extent impurities in the PNNL experimental spectra (for instance, dimer presence in the $\mathrm{HCOOH}$ spectra). In the supplementary material we provide a Python script that can be run with HAPI. The current version of HAPI is available at (www.hitran.org/hapi) along with its manual.

As managers of both databases we are happy to jointly announce that large portions of the PNNL database will be added to the cross-sectional part of the HITRAN database; we hope that this will minimize future errors associated with the use of both databases simultaneously.

\section{The Supplement related to this article is available online at doi:10.5194/cp-11-1097-2015-supplement.}

Acknowledgements. The work in the Harvard-Smithsonian Center for Astrophysics is supported by the NASA PATM program, grant number NNX13AI59G, and the NASA AURA program, grant number NNX14AI55G.

Discussions with D. Crisp, C. Hill, J. S. Wilzewski, and P. Wcisło are much appreciated.

Edited by: Y. Godderis

\section{References}

Baskakov, O. I., Markov, I. A., Alekseev, E. A., Motiyenko, R. A., Lohilahti, J., Horneman, V. M., Winnewisser, B. P., Medvedev, I. R., and De Lucia, F. C.: Simultaneous analysis of rovibrational and rotational data for the $4^{1}, 5^{1}, 6^{1}, 7^{2}$, $8^{1}, 7^{1} 9^{1}$ and $9^{2}$ states of $\mathrm{HCOOH}$, J. Mol. Struct., 795, 54-77, 2006.

Blass, W. E., Jennings, L., Ewing, A. C., Daunt, S. J., Weber, M. C., Senesac, L., Hager, S., Hillman, J. J., Reuter, D. C., and Sirota, J. M.: Absolute intensities in the $v_{7}$ band of ethylene: tunable laser measurements used to calibrate FTS broad- band spectra, J. Quant. Spectrosc. Radiat. Trans., 68, 467-472, 2001.

Brannon, J. F. and Varanasi, P.: Tunable diode laser measurements on the $951.7393 \mathrm{~cm}^{-1}$ line of ${ }^{12} \mathrm{C}_{2} \mathrm{H}_{4}$ at planetary atmospheric temperatures, J. Quant. Spectrosc. Radiat. Trans., 47, 237-242, 1992.

Brizzi, G., Arnone, E., Carlotti, M., Dinelli, B. M., Flaud, J. M., Papandrea, E., Perrin, A., and Ridolfi, M.: Retrieval of atmospheric $\mathrm{H}^{15} \mathrm{NO}_{3} / \mathrm{H}^{14} \mathrm{NO}_{3}$ isotope ratio profile from MIPAS/ENVISAT limb-scanning measurements, J. Geophys. Res. Atmos., 114, 112, 2009.

Byrne, B. and Goldblatt, C.: Radiative forcings for 28 potential Archean greenhouse gases, Clim. Past, 10, 1779-1801, doi:10.5194/cp-10-1779-2014, 2014a.

Byrne, B. and Goldblatt, C.: Radiative forcing at high concentrations of well-mixed greenhouse gases, Geophys. Res. Lett., 41, 152-160, 2014b.

Cauuet, I., Walrand, J., Blanquet, G., Valentin, A., Henry, L., Lambeau, C., de Vleeschouwer, M., and Fayt, A.: Extension to thirdorder Coriolis terms of the analysis of $v_{10}, v_{7}$, and $v_{4}$ levels of ethylene on the basis of Fourier transform and diode laser spectra, J. Mol. Spectrosc., 139, 191-214, 1990.

Devi, V. M., Rinsland, C. P., Smith, M. A, Benner, D. C., and Fridovich, B.: Tunable diode laser measurements of airbroadened linewidths in the $v_{6}$ band of $\mathrm{H}_{2} \mathrm{O}_{2}$, Appl. Opt., 25, 1844-1847, 1986.

Jacquemart, D., Kwabia Tchana, F., Lacome, N., and Kleiner, I.: A complete set of line parameters for $\mathrm{CH}_{3} \mathrm{Br}$ in the $10 \mu \mathrm{m}$ spectral region, J. Quant. Spectrosc. Radiat. Trans., 105, 264-302, 2007.

Johnson, T. J., Sams, R. L., Burton, S. D., and Blake, T. A.: Absolute integrated intensities of vapor-phase hydrogen peroxide $\left(\mathrm{H}_{2} \mathrm{O}_{2}\right)$ in the mid-infrared at atmospheric pressure, Anal. Bioanal. Chem., 395, 377-386, 2009.

Johnson, T. J., Profeta, L. T. M., Sams, R. L., Griffith, D. W. T., and Yokelson, R. L.: An infrared spectral database for detection of gases emitted by biomass burning, Vib. Spectrosc., 53, 97-102, 2010.

Klee, S., Winnewisser, M., Perrin, A., and Flaud, J.: Absolute line intensities for the $v_{6}$ band of $\mathrm{H}_{2} \mathrm{O}_{2}$, J. Mol. Spectrosc., 195, 154161, 1999.

Kochanov, R., Hill, C., Gordon, I., Wcisło, P., Rothman, L., and Wilzewski, J.: HITRAN Application Programming Interface 
(HAPI) - Beta version, Zenodo, available at: http://dx.doi.org/ 10.5281/zenodo.17719, 2015.

Kwabia Tchana, F., Kleiner, I., Orphal, J., Lacome, N., and Bouba, O.: New analysis of the Coriolis-interacting $v_{2}$ and $v_{5}$ bands of $\mathrm{CH}_{3}^{79} \mathrm{Br}$ and $\mathrm{CH}_{3}^{81} \mathrm{Br}$, J. Mol. Spectrosc., 228, 441-452, 2004.

Laraia, A. L., Gamache, R. R., Lamouroux, J., Gordon, I. E., and Rothman, L. S.: Total internal partition sums to support planetary remote sensing, Icarus, 215, 391-400, 2011.

Legrand, J., Azizi, M., Herlemont, F., and Fayt, A.: Saturation spectroscopy of $\mathrm{C}_{2} \mathrm{H}_{4}$ using a $\mathrm{CO}_{2}$ laser sideband spectrometer, J. Mol. Spectrosc., 171, 13-21, 1995.

Li, G., Gordon, I. E., Hajigeorgiou, P. G., Coxon, J. A., and Rothman, L. S.: Reference spectroscopic data for hydrogen halides, Part II: The line lists, J. Quant. Spectrosc. Radiat. Trans., 130, 284-295, 2013.

Meadows, V. S. and Crisp, D.: Ground-based near-infrared observations of the Venus nightside: the thermal structure and water abundance near the surface, J. Geophys. Res., 101, 4595, doi:10.1029/95JE03567, 1996.

Ngo, N. H., Lisak, D., Tran, H., and Hartmann, J. M.: An isolated line-shape model to go beyond the Voigt profile in spectroscopic databases and radiative transfer codes, J. Quant. Spectrosc. Radiat. Trans., 129, 89-100, 2013.

Perrin, A. and Mbiaké, R.: The $v_{5}$ and $2 v_{9}$ bands of the ${ }^{15} \mathrm{~N}$ isotopic species of nitric acid $\left(\mathrm{H}^{15} \mathrm{NO}_{3}\right)$ : line positions and intensities, J. Mol. Spectrosc., 237, 27-35, 2006.

Perrin, A., Valentin, A., Flaud, J. M., Camy-Peyret, C., Schriver, L., Schriver, A., and Arcas, P.: The 7.9 $\mu \mathrm{m}$ band of hydrogen peroxide: line positions and intensities, J. Mol. Spectrosc., 171, 358373, 1995.

Perrin, A., Flaud, J.-M., Camy-Peyret, C., Schermaul, R., Winnewisser, M., Mandin, J.-Y., Dana, V., Badaoui, M., and Koput, J.: Line intensities in the far-infrared spectrum of $\mathrm{H}_{2} \mathrm{O}_{2}$, J. Mol. Spectrosc., 176, 287-296, 1996.

Perrin, A., Flaud, J.-M., Bakri, B., Demaison, J., Baskakov, O., Sirota, S.., Herman, M., and Auwera, J. V.: New high-resolution analysis of the $v_{7}$ and $v_{9}$ fundamental bands of trans-formic acid by Fourier transform infrared and millimeter-wave spectroscopy, J. Mol. Spectrosc., 216, 203-213, 2002.

Perrin, A., Keller, F., and Flaud, J.-M.: New analysis of the $v_{2}, v_{3}$, $v_{4}$, and $v_{6}$ bands of formaldehyde $\mathrm{H}_{2}^{12} \mathrm{C}^{16} \mathrm{O}$ line positions and intensities in the $5-10 \mu \mathrm{m}$ spectral region, J. Mol. Spectrosc., 221, 192-198, 2003.

Rotger, M., Boudon, V., and Vander Auwera, J.: Line positions and intensities in the $v_{12}$ band of ethylene near $1450 \mathrm{~cm}^{-1}$ : an experimental and theoretical study, J. Quant. Spectrosc. Radiat. Trans., 109, 952-962, 2008.

Rothman, L. S., Rinsland C. P., Goldman A., Massie S. T., Edwards, D. P., Perrin, A., Dana, V., Gamache, R. R., and Jucks, K. W.: The HITRAN molecular spectroscopic database and HAWKS (HITRAN atmospheric workstation): 1996 Edn., J. Quant. Spectrosc. Radiat. Trans., 60, 665-710, 1998.

Rothman, L. S., Jacquemart, D., Barbe, A., Chris Benner, D., Birk, M., Brown, L. R., Carleer, M. R., Chackerian, C., Chance, K., Coudert, L. H., Dana, V., Devi, V. M., Flaud, J.-M., Gamache, R. R., Goldman, A., Hartmann, J.-M., Jucks, K. W., Maki, A. G., Mandin, J.-Y., Massie, S. T., Orphal, J., Perrin, A., Rinsland, C. P., Smith, M. A. H., Tennyson, J., Tolchenov, R. N.,
Toth, R. A., Vander Auwera, J., Varanasi, P., and Wagner, G.: The HITRAN 2004 molecular spectroscopic database, J. Quant. Spectrosc. Radiat. Trans., 96, 139-204, 2005.

Rothman, L. S., Gordon, I. E., Barbe, A., Benner, D. C., Bernath, P. F., Birk, M., Boudon, V., Brown, L. R., Campargue, A., Champion, J.-P., Chance, K., Coudert, L. H., Dana, V., Devi, V. M., Fally, S., Flaud, J.-M., Gamache, R. R., Goldman, A., Jacquemart, D., Kleiner, I., Lacome, N., Lafferty, W. J., Mandin, J.-Y., Massie, S. T., Mikhailenko, S. N., Miller, C. E., Moazzen-Ahmadi, N., Naumenko, O. V., Nikitin, A. V., Orphal, J., Perevalov, V. I., Perrin, A., Predoi-Cross, A., Rinsland, C. P., Rotger, M., Šimečková, M., Smith, M. A. H., Sung, K., Tashkun, S. A., Tennyson, J., Toth, R. A., Vandaele, A. C., and Vander Auwera, J.: The HITRAN 2008 molecular spectroscopic database, J. Quant. Spectrosc. Radiat. Trans., 110, 533-572, 2009.

Rothman, L. S., Gordon, I. E., Babikov, Y., Barbe, A., Chris Benner, D., Bernath, P. F., Birk, M., Bizzocchi, L., Boudon, V., Brown, L. R., Campargue, A., Chance, K., Cohen, E. A., Coudert, L. H., Devi, V. M., Drouin, B. J., Fayt, A., Flaud, J.M., Gamache, R. R., Harrison, J. J., Hartmann, J.-M., Hill, C., Hodges, J. T., Jacquemart, D., Jolly, A., Lamouroux, J., Le Roy, R. J., Li, G., Long, D. A., Lyulin, O. M., Mackie, C. J., Massie, S. T., Mikhailenko, S., Müller, H. S. P., Naumenko, O. V., Nikitin, A. V., Orphal, J., Perevalov, V., Perrin, A., Polovtseva, E. R., Richard, C., Smith, M. A. H., Starikova, E., Sung, K., Tashkun, S., Tennyson, J., Toon, G. C., Tyuterev, V. G., and Wagner, G.: The HITRAN2012 molecular spectroscopic database, J. Quant. Spectrosc. Radiat. Trans., 130, 4-50, 2013.

Rusinek, E., Fichoux, H., Khelkhal, M., Herlemont, F., Legrand, J., and Fayt, A.: Subdoppler study of the $v_{7}$ band of $\mathrm{C}_{2} \mathrm{H}_{4}$ with a $\mathrm{CO}_{2}$ laser sideband spectrometer, J. Mol. Spectrosc., 189, 6473, 1998.

Sharpe, S. W., Johnson, T. J., Sams, R. L., Chu, P. M., Rhoderick, G. C., and Johnson, P. A.: Gas-phase databases for quantitative infrared spectroscopy, Appl. Spectrosc., 58, 1452-1461, 2004.

Tennyson, J., Bernath, P. F., Campargue, A., Csaszar, A. G., Daumont, L., Gamache, R. R., Hodges, J. T., Lisak, D., Naumenko, O. V., Rothman, L. S., Tran, H., Zobov, N. F., Buldyreva, J., Boone, C. D., De Vizia, M., Gianfrani, L., Hartmann, J.-M., McPheat, R., Weidmann, D., Murray J., Ngo, N. H., and Polyansky, O. L.: Recommended isolated-line profile for representing high-resolution spectroscopic transitions, Pure Appl. Chem., 86, 1931-1943, 2014.

Xu, L. H., Lees, R. M., Wang, P., Brown, L. R., Kleiner, I., and Johns, J. W. C.: New assignments, line intensities, and HITRAN database for $\mathrm{CH}_{3} \mathrm{OH}$ at $10 \mu \mathrm{m}$, J. Mol. Spectrosc., 228, 453-470, 2004. 